\title{
ONLINE LEARNING QUESTIONNAIRES BASED ON RENEWABLE ENERGY RESEARCH EQUIPMENT
}

\author{
F. Javier Maseda Rego ${ }^{1}$, Itziar Martija López ${ }^{1}$, Patxi Alkorta Egiguren ${ }^{2}$, Izaskun Garrido \\ Hernández ${ }^{1}$, \& Aitor J. Garrido Hernández ${ }^{1}$ \\ ${ }^{1}$ Automatic Control Group (ACG), Institute of Research and Development of Processes, Faculty of \\ Engineering in Bilbao, University of the Basque Country (UPV/EHU) (Spain) \\ ${ }^{2}$ Engineering School of Gipuzkoa, University of the Basque Country (UPV/EHU) (Spain)
}

\begin{abstract}
This paper resumes the main ideas to develop different sets of questionnaires based on renewable energy research equipment to improve online learning in engineering education. These educational activities, on the one hand, promote the connection between technological and education environments and, on the other hand, improve the motivation for studying theoretical and practical issues. The implementation of the proposed teaching and learning tasks will contribute to integrate students with different motivation and attitudes since the use of the close physical equipment for questionnaires development has an evident educational benefit when using it as a study model.

The evolution of technological environments to educational units involves a functional Disassembly/Analyze/Assembly conversion to different modules adapted to specific subjects, the link with the theoretical knowledge, and finally, the questionnaire construction.

The combination proposed offers the following positive results in master or grade studies: the effectiveness of competences training is improved, the students experimental work progresses significantly and the students' motivation for better theory comprehension is more intensively developed. The use of these kind of questionnaires as educational tools is not new and their advantages are well known: the quick feedback results and the systematic data collection to support the educational proposal effectiveness, among others. Nevertheless, this tool has become a necessity with the massive use of online education.

In summary, promoting the evolution of engineering education to online techniques and the use of renewable energy research equipment to promote the students' vision on social necessities are two examples of educational goals stated in this paper.
\end{abstract}

Keywords: Engineering education, renewable energy, learning methodologies.

\section{Introduction}

The new generation of students has grown up with a great knowledge of digital technology and a no less concern for environmental issues. This reality has been taken into account in academic studies offered by the universities (Alameri, Masadeh, Hamadallah, Ismail \& Fakhouri, 2020). The inclusion of grade and master programs related to Renewable Energy Generation and Information and Communication Technologies topics has a great acceptance among the students. In addition, the Covid19 pandemic has given an impulse to the online education in the last year, in many traditional face-to-face university studies (Kövecses, Lampert, Pongráez \& Lörinez, 2020).

The growth and importance of renewable energy generation, fundamentally solar (Ott, Broman, Blum, 2018), wind and marine (Lekube, Garrido, Garrido, Otaola \& Maseda, 2018), are motivated by the need to overcome the negative impact on the environment associated with fossil fuels. This fact has led to an increased interest in these technological areas and to the importance of the required engineering education in these fields (Gutiérrez, Ghotge, Siemens, Blake-Rath \& Pätz, 2018).

Renewable energy research equipment in is not always used in educational areas, being labelled as complex machines. The methodology of dissection of industrial artifacts based on reverse engineering techniques has been applied with the objective of improving the comprehension of their functionality (Dalrymple, Sears \& Evangelou, 2011). Functional Disassemble/Analyze/Assemble (fDAA) is a 
well-adapted educational methodology applied to renewable energy generation equipment. The "functional" term in this context means that DAA activities will be performed based on the relationship between input and output signals for each block of the energy system (Martija, Maseda \& Martija, 2013). In addition, the fDAA activities are developed to be integrated in different teaching and learning methodologies, such as, Project Based Learning (PjBL) (Maseda, Martija \& Martija, 2014), Challenge Based Learning (CBL) and Research Based Learning (RBL) (Fojcik, Fojcik, \& Pollen, 2020). This combination, active educational methodology and fDAA activities, creates a general framework for obtaining a better and deeper comprehension of theoretical and practical concepts based on the division of complex equipment into basic functional components. The limit of this division depends on the academic interest for a specific subject.

In this framework, the online learning questionnaires have become one of the most important issues, because the modularity and analysis of each block or component of the equipment are used for developing different questionnaires (Esnaola-Arribillaga and Bezanill, 2020). These questionnaires are a powerful tool because they are easy to use anywhere and anytime, give a quick feedback for students, and allow teaching staff to have a complete assessment picture about the acquired knowledge and competences, among others. However, as main disadvantages, there are the considerable amount of time for generating a complete set of online questionnaires for a specific subject and the potential fraud in their resolution (Pehlivanova, 2019).

The following sections present the research equipment used as case of study, the online questionnaires, the discussion about schedule, feedback, assessment and potential fraud, and finally, the conclusions.

\section{Educational environment}

The educational activity proposed can become a great advantage for understanding renewable energy generators and their energy converters in a common framework.

At the Faculty of Engineering in Bilbao, in the University of the Basque Country, one of the renewable energy research equipment used for educational proposals is a solar plant implemented by $2 \mathrm{~kW}$ solar panels and different power electronic converters. This research equipment is integrated in the educational environment for teaching and learning activities. Figure 1 shows the integration where the solar scenario is combined with the PjBL methodology, fDAA activities and the assessment tools.

Figure 1. Educational environment.

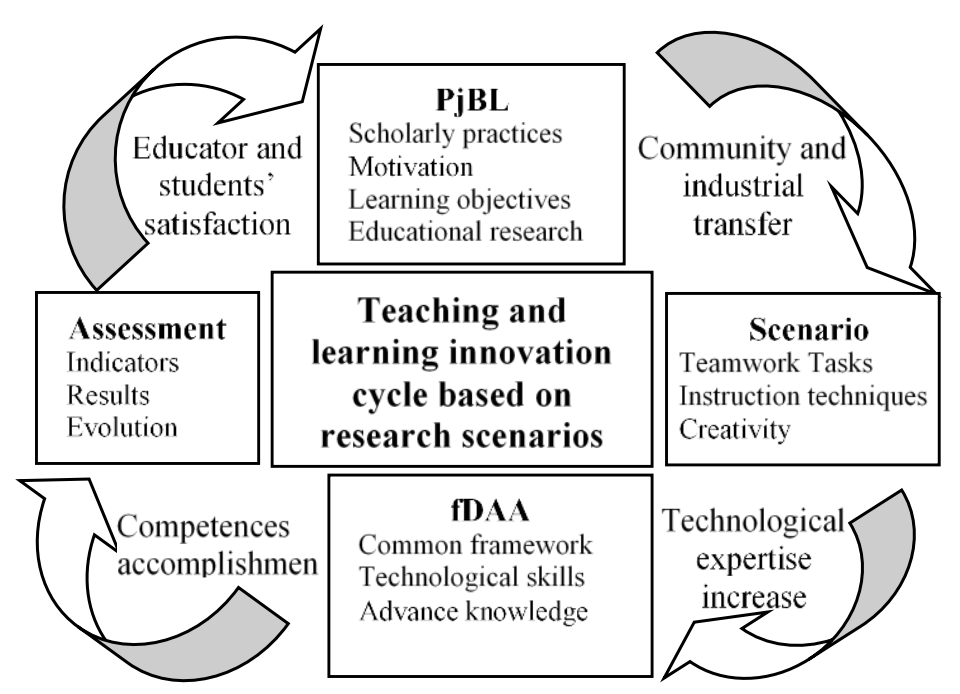

The online questionnaires are included in this environment in the assessment module, but their real practical use is in the entire educational environment. They are part of the PjBL methodology because the continuous evaluation is based on difficulty-adapted online questionnaires which are programmed along the semester. The educational scenario activities are the main pole of attraction for students. On these scenarios, numerical and theoretical questions applied to real cases are developed for PjBL implementation. The fDAA activities help to modulate questionnaires into different technological topics. 


\section{Renewable energy research equipment and online questionnaires}

The systematic collection of evidences to corroborate the educational proposal effectiveness in the different aspects of the teaching-learning process should be implemented (Weronika, 2020). Among these evidences, the online questionnaires constitute a relevant help. Moodle platform is one of the most commonly applied tools to develop different sorts of questionnaires and their subsequent analysis (Luminita Gogan, Sirbu \& Draghici, 2015).

The online questionnaires have different aspects, which must be carefully studied before using them: Are they easy to develop? Do they improve information transfer? Are they a good assessment tool? Do they favor the communication and the interaction? Do they support the preparation of the matter of study? Do they develop skills related to Bloom's taxonomy, such as, knowledge, comprehension, application, analysis, among others? The answer to these questions depend on the educational environment where the questionnaires are used.

The analysis of the questionnaires results gives an extensive vision about different educational aspects: students' assessment distribution bias, standard deviation or variance of this distribution, difficulty index of different matter topics or their discriminative performance, among others.

Moodle questionnaires present a wide sort of questions. Figure 2 shows a graphic synopsis of the most commonly used questions and their relationship with the renewable energy research equipment.

Figure 2. Questionnaires and the relationship between renewable energy research equipment and questions.
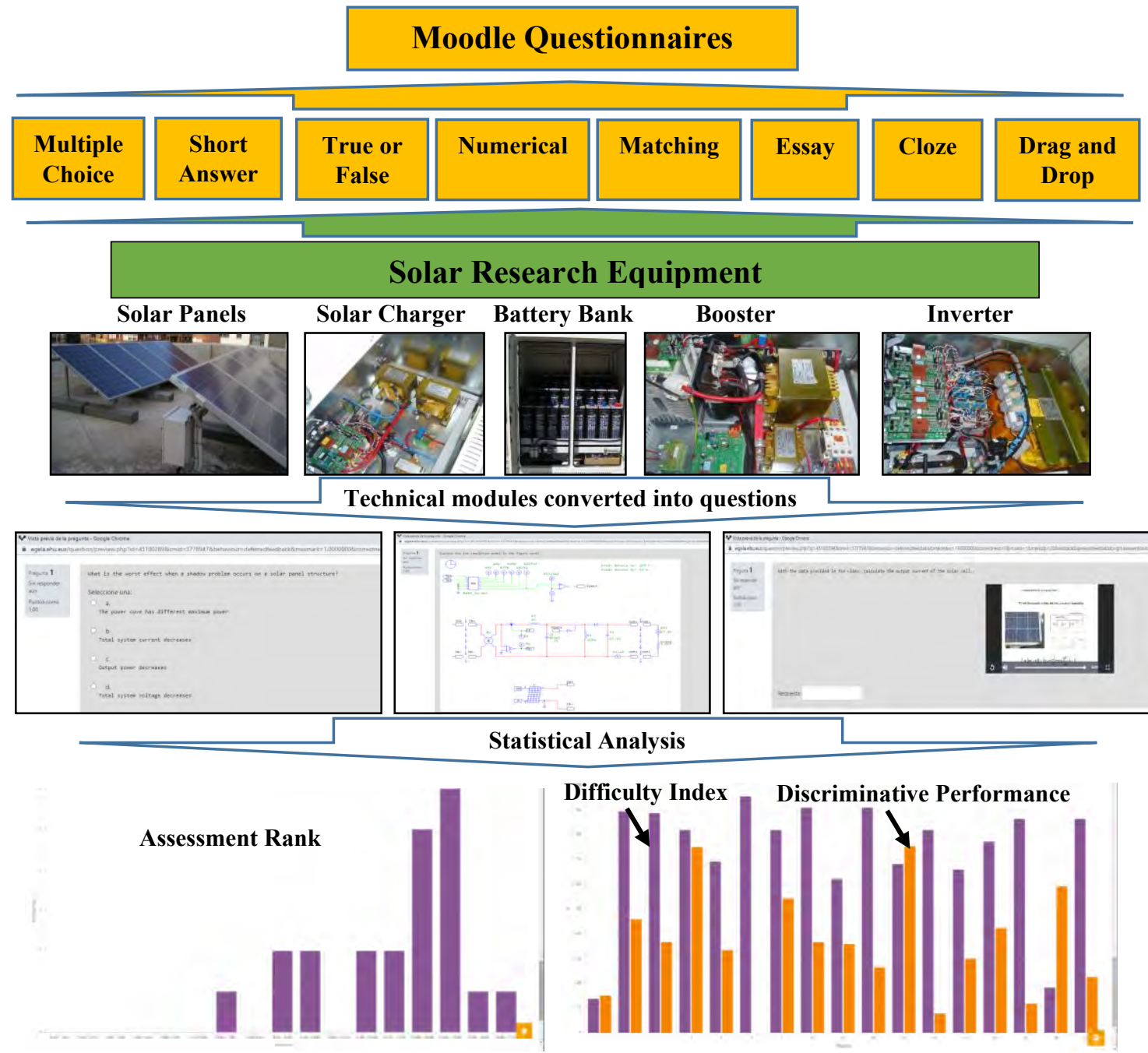

The possibility of integrating images, videos, simulation models, in any sort of question, such as, Multiple Choice, Short Answer, True or False, or Matching, improves the aesthetic appearance of questionnaires and provides them with a more attractive dynamic for students. The ability to develop engineering problems in a set of Numerical and Cloze questions makes them easier to understand and, 
at the same time, more feasible to resolve. The different Drag and Drop questions allow to configure block diagrams and simulation models, extending the possibilities of the questionnaires within the experimental activities. In summary, the quantity and variety of the sort of questions that are available in Moodle allow integrating the majority of the traditional engineering exams in questionnaires. Finally, the statistical analysis of questionnaire results are easy to obtain. In Figure 2 it is possible to observe a students' mark rank graphic and the relationship between difficulty index and discriminative performances of the different questions.

\section{Discussion: Schedule, feedback, assessment and potential fraud}

Most of the universities base their teaching and learning methodologies on face-to-face interaction. However, the online activities are growing up and platforms like Moodle have become ubiquitous tools (Esnaola-Arribillaga and Bezanill, 2020). This increase in the online activities use results in different issues that must be discussed. Schedule, feedback, assessment and potential fraud in the questionnaires are some important issues for a successfully implementation.

The schedule must be carefully studied because the questionnaires should put a constant pressure on students for obtaining a continuous effective attention. The excessive number of questionnaires with an established date can produce an excess of psychological pressure, which can develop a certain disappointment and a loss of interest in the subject studied, in case of repetitive low results.

The level of feedback is other aspect that should be analyzed because the answers could disable the question for other questionnaires, and this means having to reconstruct the questionnaires every year. On the other hand, the feedback is necessary for students to analyze their own faults and to motivate themselves for theory thoughtful study.

Marks are a fundamental issue for students and the online assessment including questionnaires have an increasing weight in the final students' marks. It is unlikely to obtain $100 \%$ right answers on online questionnaire because it is difficult that students understand all the questions without doubts, what could lead them to take a wrong solution. In this way, the lecturers should have solutions for this situation and in particular, if the questionnaires have negative punctuation in wrong answers.

Finally, a considerable disadvantage associated with online questionnaires is the potential fraud in its different modalities (Pehlivanova, 2019). The pandemic Covid19 became an inflection point last year when these educational tools had to be applied in a massive way and so, the possibility of fraud was increased. However, this situation should not prevent the use of these educational platforms. Different methodologic, organizational and technologic solutions could be applied (Pehlivanova, 2019), (Matos, Carvalho, Torräo \& Vieira, 2012).

As a real example of application -Power Electronics, second semester subject, Grade of Industrial Electronics and Automation, in the Faculty of Engineering in Bilbao-, the schedule used is shown in Table 1. This schedule was applied from January 2020 to May 2020 during Covid19 pandemic. Timetable only shows the programmed questionnaires and how they are considered in the final student mark.

Table 1. Schedule proposed for online questionnaires and students global assessment.

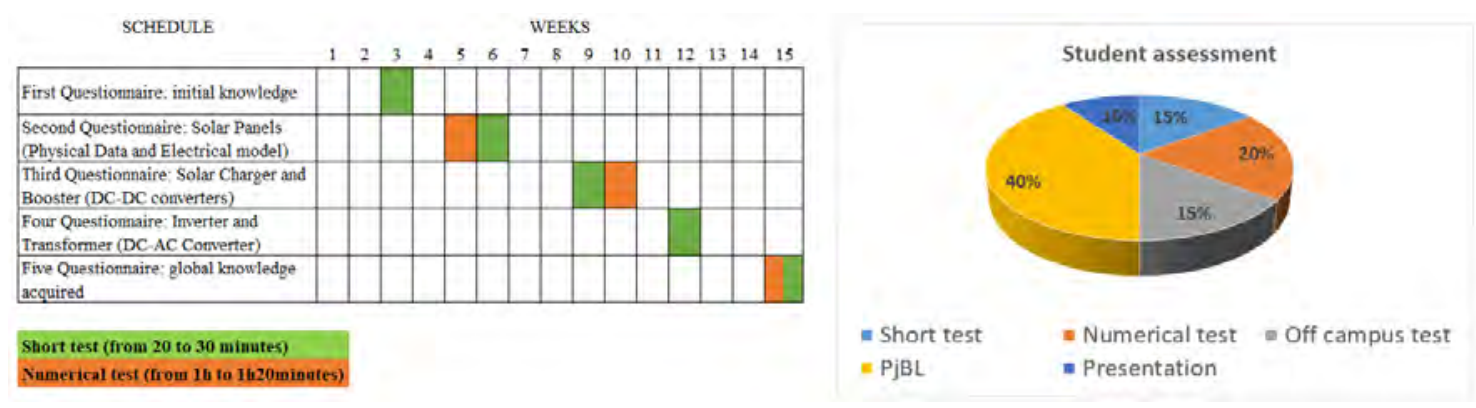

An important aspect in the ECTS (European Credit Transfer System) is the off-campus study time that the student weekly spends in different academic tasks. In these tasks the online asynchronous questionnaires can play an important role for working specific subject aspects, if they result interesting for students. The renewable energy research equipment is very attractive for them and the questionnaires have become something similar to an online game for playing. In addition, these off-campus activities, related to the online questionnaire, help in a more effective $\mathrm{PjBL}$ implementation to complement the face-to-face activities. 


\section{Conclusions}

The progressive use of online platforms and in particular of online questionnaires has improved the academic efficiency in both teaching and learning processes. This improvement has been reflected in the student marks. Additionally, students' vision about the assessment methods has also positively evolved.

The renewable energy research equipment links the theoretical knowledge to a real solar energy plant and, in this way, facilitate the required competencies for professional development of future engineers in this technological area. In the next few years, the new engineering advances in renewable energy generation will be a crucial necessity. The engineering education will have to give the methodological tools for this development, and the online platforms will help in this task.

The environment created allows collecting the experiences of students and teachers, promoting its adaptation and evolution. Based on this same principle, the indicators and tools for evaluating the proposal will also evolve during the next years.

Finally, the Covid19 pandemic has supposed a great challenge for many universities based on face-to-face education in which the questionnaires have become a useful tool for evolving towards an online education. In addition, this change has come to stay.

\section{Acknowledgements}

This work was supported in part by the Basque Government, through project IT1207-19 and by the MCIU/MINECO through RTI2018-094902-B-C21/RTI2018-094902-B-C22 (MCIU/AEI/FEDER, UE).

\section{References}

Alameri, J., Masadeh R., Hamadallah, E., Ismail, H. B., \& Fakhouri H. N. (2020). Students` Perceptions of E-learning platforms (Moodle, Microsoft Teams and Zoom platforms) in The University of Jordan Education and its Relation to self-study and Academic Achievement during COVID-19 pandemic. Advanced Research \& Studies Journal, 11 (5), 21-33.

Dalrymple, O., Sears D. A., \& Evangelou, D. (2011). The Motivational and Transfer Potential of Disassemble/Analyze/Assemble (DAA) Activities. Journal of Engineering Education, 100 (4), 741-759.

Esnaola-Arribillaga, I., \& Bezanill, M. J. (2020). Levels of Moodle Use to Support University Face-to-Face Teaching. IEEE Revista Iberoamericana de Tecnologias del Aprendizaje, 15 (3), 129-137.

Fojcik, M., Fojcik, M. K., \& Pollen, B. (2020). Students in Research-Experience with Research-Based Teaching. Education and New Development (END), 122-126.

Gutiérrez, M., Ghotge R., Siemens, A., Blake-Rath, R., \& Pätz, I. (2018). Influence of diversity in lectures on the students` learning process and on their perspectives about renewables energies in an international context - The students` view. Solar Energy, 173, 268-271.

Kövecses, V. G., Lampert, B., Pongráez, A., \& Lörinez, C. (2020). University Lectures' Distance Learning Experiences Gained during the COVID-19 Pandemic Period. IEEE International Conference on Cognitive Infocomunications, 173, 268-271.

Lekube, J., Garrido, A. J., Garrido, I., Otaola, E., \& Maseda, J. (2018). Flow Control in Wells Turbines for Harnessing Maximum Wave Power. Sensors, 18 (2), 535.

Luminita Gogan, M., Sirbu, R., \& Draghici, A. (2015). Aspects concerning the use of Moodle platform Case study. Procedia Technology, (19), 1142-1148.

Martija, I., Maseda, F. J., \& Martija, I. (2013). Functional Dissection of Power Electronic Systems as Learning Technique. IEEE Global Engineering Education Conference (EDUCON), 11-15.

Maseda, F. J., Martija, I., \& Martija, I. (2014). An Active Learning Methodology in Power Electronic Education. IEEE Frontiers in Education (FIE), 1-5.

Matos, R., Carvalho, F., Torräo, S., \& Vieira, T. (2012). Moodlewather: One Year Experience of Detecting and Preventing Fraud When Using Moodle Quizzes. International Conference on Education and New Learning Technologies (EDULEARN).

Ott, A., Broman, L., \& Blum, K. (2018). A pedagogical approach to solar energy education. Solar Energy, 173, 740-743.

Pehlivanova, T. (2019). Prevention of Cheating when Using Quizzes in Moodle. International Conference on Virtual Learning (ICVL).

Weronika, F. (2020). Moodle quizzes and their usability for formative assessment of academic writing. Assessing Writing. (46). 